\title{
Are we making the same mistakes in fighting COVID-19 as in past pandemics? Lessons from HIV show the urgent need to invest in
} HPSR

\section{David Stucklere, ${ }^{a, c}$ Martin McKee ${ }^{b}$ and Alexander Kentikelenis ${ }^{a}$}

a Department of Social and Political Sciences, Università Bocconi, Milan, Italy

${ }^{b}$ London School of Hygiene and Tropical Medicine, UK

c Corresponding author: david.stuckler@unibocconi.it

\section{Article history}

Publication date: 10 November 2021

Citation: Stuckler D, McKee M,

Kentikelenis A. Are we making the same mistakes in fighting COVID-19 as in past pandemics? Lessons from HIV show the urgent need to invest in HPSR. Public Health Res Pract. 2021;31(4):e3142116. https://doi. org/10.17061/phrp3142116

\section{Key points}

- Similar to the HIV epidemic, the fight against coronavirus disease 2019 (COVID-19) has placed heavy emphasis on drugs and medicines, but less on strengthening health systems

- The health systems and policy research (HPSR) field developed in the mid-1990s to help overcome the weaknesses in the fight against human immunodeficiency virus (HIV)

- Current investment in HPSR is very low: $\$ 0.02$ of every $\$ 1$ in global health is for health systems strengthening

- We argue that greater investment in HPSR is needed to address the shortcomings of the global COVID-19 response

\section{Abstract}

Are we repeating the mistakes of the human immunodeficiency virus (HIV) epidemic in our approach to combating coronavirus disease 2019 (COVID-19)? Is the world's emphasis on developing vaccines overshadowing investment in the health systems that can deliver them? We analyse a report on the politics of investing in health policy and systems research (HPSR) and conclude by outlining three critical actions, using the Stuckler-McKee model of social change in health. These are: exploiting a political window of opportunity; changing the conversation; and mobilising a campaign to drive the agenda. When implemented together, these actions could help accelerate investment in health systems to combat the immediate COVID-19 pandemic and prepare health systems for the next crisis.

\section{Introduction}

To many, she was simply known as the "pocket rocket". That's what the other nurses called Maria, 47, a mental health specialist in a European country (note: Maria's name has been changed to protect her identity). When others called in sick or went on holidays, Maria would take on extra shifts and work overtime. In 2020, when coronavirus disease 2019 (COVID-19) cases began spreading like wildfire, Maria took it upon herself to help, but this time, her family was worried. Several of Maria's colleagues had fallen ill with COVID-19, and she had a pre-existing condition that put her at high risk.

The good news was that, like many frontline healthcare workers, Maria was set to be one of the first to receive the Pfizer-BioNTech COVID-19 vaccine. However, on a morning in November 2020, Maria tested positive to COVID-19.

It all happened so fast. Within a week Maria could barely breathe and was admitted to her local hospital. It seemed like she was getting better but then her breathing took a turn for the worse and she was moved to intensive care 
and placed on a ventilator. Maria died in December, just days after the vaccine was approved and rolled out.

\section{Supply and demand challenges in the fight against COVID-19}

The European Medicines Agency became one of the first regulators to authorise the Pfizer-BioNTech COVID-19 vaccine, just before the end of $2020 .{ }^{1}$ But that was only the beginning. Governments then had to deliver the vaccines they had ordered to their populations. Although they had months to plan for it, their progress was extremely variable. By mid-May 2021, Malta had fully vaccinated $32.5 \%$ of its population, compared with Bulgaria at $6.1 \% .^{2}$ Such delays are inexcusable. Every moment counts in the fight against a pandemic.

Maria is one of several nurses who put their lives on the line in service of others. For too many healthcare workers like Maria, the vaccine came too late. A WHO analysis suggests there were 49374 healthcare worker deaths in Europe due to COVID-19 between January 2020 and May $2021^{3}$ - a figure that undoubtedly includes many healthcare workers who lost their lives after vaccines were approved and available.

At the time of writing, in October 2021, the situation has evolved: supply is now sufficient across most western European countries, but demand lags behind. Vaccine hesitancy continues to stymie progress towards eradicating COVID-19 in Europe. It is estimated that between $25 \%$ and $92 \%$ of people in European countries have been fully vaccinated, with marked variations across countries. ${ }^{4}$ While vaccine manufacturers and governments continue to emphasise vaccine development to keep pace with new variants, the challenge of inadequate take-up persists. Perhaps surprisingly, this situation even applies to healthcare workers: it is estimated that as many as 1 in 5 healthcare workers in the US refuse to take up the COVID-19 vaccine. ${ }^{5}$

The COVID-19 pandemic is inestimably worse in lowand middle-income countries (LMICs), where challenges related to both vaccine supply and demand loom large. ${ }^{6}$ In some cases, the problem is lack of supply; vaccine manufacturers, and the governments that provide much of the funding for vaccine development, have failed to increase global supply. Manufacturers have been wary about giving up intellectual property rights linked to patents and trade secrets, even though many believe that this knowledge should be treated as a global public good. ${ }^{7}$ This means manufacturing plants that could be repurposed in several middle-income countries are prevented from joining the effort to vaccinate the world. And this is only part of the problem. Many countries have struggled to administer even those vaccines they have received, for example, in Malawi 20000 doses were destroyed and in South Africa about 60000 doses were destroyed because they had expired before they could be administered. ${ }^{8}$

Both Europe and the rest of the world need real solutions to the above problems but where might they come from? In this narrative perspective, we turn to the past for clues, looking for insights from the human immunodeficiency virus (HIV) pandemic.

\section{Insights from the HIV pandemic: low investments in health systems strengthening}

History seems to be repeating itself; these struggles in controlling COVID-19 have been witnessed before. Three decades ago, HIV was ravaging sub-Saharan Africa. No specific treatment existed but, as with the COVID-19 vaccines, a remarkable international scientific effort created the first antiretroviral therpaies. However, as with COVID-19 vaccines, they were, at least initially, extremely unequally distributed. Countries in greatest need were unable to afford the prohibitively high prices for antiretrovirals and manufacturers were unwilling to give up their rights to the intellectual property involved. ${ }^{9}$

Eventually, as in Europe now, the problems of supply and affordability were addressed, aided by the creation of new organisations like The Global Fund, which had a large endowment to help supply and distribute lifesaving medicines. By the mid-1990s, highly active antiretroviral therapy (HAART) promised an almost normal lifespan for those living with HIV/AIDS. ${ }^{10}$ Yet supply remained inadequate in LMICs for decades. ${ }^{11}$

Despite international efforts to procure medicines for HIV, there was a large gap between the theory and the practice; between medicines availability and actual uptake, especially, but not only, for those living on the margins of societies in resource-deprived countries. The arrival of a consignment of medicines at an international airport did not mean they would reach those in need: if there was no health worker present or pharmacy shelves were empty, people whose lives depended on regular treatment died. ${ }^{12}$ Health systems then, as today, lacked the infrastructure to deliver these medicines to people living with HIV.

Belatedly, the world's attention turned to these problems. When the World Health Organization (WHO) missed its initial targets to achieve HIV antiretroviral coverage in the early 2000 s (the ' 3 by 5 ' initiative to provide antiretroviral treatment to 3 million people living with HIV/AIDS in LMICs by 2005) ${ }^{13}$, it became clear that winning the fight against HIV/AIDS would depend on strengthening health systems. Health systems policy, regrettably, had languished near the bottom of government policy agendas. To strengthen it, the global health community needed to understand what was wrong and how it might be fixed. It soon became clear that there were few easy solutions and the data needed to identify 
health system bottlenecks and barriers were almost completely missing.

Much of the international community had sought to find a 'magic bullet' to solve HIV/AIDS but this did not fit with a wider health systems approach. Health systems are complex human systems, shaped by their history and context. The answers were often not simple and depended on local contexts. We needed to know not only what worked to deliver medicines effectively and at affordable cost but, as importantly, when this worked for whom, where and in what circumstances. These realisations led to the founding of an entire new field, health policy and systems research (HPSR), which emerged in the mid-1990s against the backdrop of the HIV epidemic. ${ }^{14}$ HPSR was specifically developed to tackle pressing health systems questions such as why, for example, some people were able to obtain high quality affordable treatment while others could not.

Returning to the present, it seems that we have forgotten the lessons of HIV/AIDS and HPSR's crucial importance. A quick search of the internet will generate numerous pictures of vaccines being unloaded from planes across the world. But those vaccines will only be of use if we get them into people's arms. A successful vaccination strategy requires much more than an effective vaccine; it requires a well-functioning health system. ${ }^{14}$ This involves many elements: a population register; a mechanism to decide who will benefit and the priority for allocating vaccines; a process for recording side-effects; and links to infectious disease surveillance to detect breakthrough cases. All this requires leadership, with appropriate policies and managerial strategies, coupled with evaluation and monitoring. A failure to put all of these in place will lead to too many stories like that of Maria. And crucially, it will be hopelessly unable to respond to a complex and rapidly evolving set of cultural and political barriers to vaccine uptake.

Yet regrettably, it appears the world is once again lagging behind in investing in HPSR. In the next section we describe the results of our recent review of the state of funding and activity for HPSR during the COVID-19 pandemic, undertaken in collaboration with the WHO Alliance for Health Policy and Systems Research.

\section{The current state of inadequate investment in HPSR}

Our HPSR snapshot and profiling sought to investigate three main questions: a) what are experts saying about HPSR? b) what are donors and funders doing to support HPSR? and c) what are the main barriers to scaling it up?

To answer these questions our researchers performed a systematic review of the literature about current barriers and activity in HPSR, and conducted 30 semi-structured interviews with prominent global health funders, including The Global Fund, Bill \& Melinda Gates Foundation,
UNICEF and others. The full details are described elsewhere ${ }^{15}$, but we briefly summarise them here.

The results were surprising. We found a large disconnect between the academic interviewees' rhetoric, which often called for investment in health systems, and what was happening at the global level:

- Consistent with prior evidence, we found less than $\$ 0.02$ for every $\$ 1$ in global health funding went into wider investment in health systems or HPSR

- Donors and funders felt confused about what HPSR meant or was, and often invested in it belatedly when their health campaigns weren't working as planned

- Many funders didn't believe they had a mandate or capacity to undertake HPSR, despite HPSR being essential for delivering effective interventions

- A few global-health institutions made HPSR a priority, such as the UK Department for International Development (now merged with the Foreign Office and subject to steep budget cuts), but this very easily dissipated as political winds changed direction

- Health systems experts made widespread calls to action for investing in HPSR, asking WHO to take leadership and make HPSR a global priority. But unlike for many other areas of development assistance, such as food or clean water supply, there was little effort to create a narrative that captured HPSR's impact (or lack of it) on ordinary people's lives.

To get the most up-to-date picture possible of HPSR activity in global health, we also performed a systematic search of the DevEx database, the main repository for global health and development funding, for 2020. The DevEx database, although not comprehensive, is the best available resource for capturing global health activities in real time. We also found some other fragments of HPSR activity, for example, supported by the Wellcome Trust, but these were the exception. Consistent with the quantitative estimates from the systematic review showing very low funding, the overwhelming impression was that HPSR continues to be neglected. It is hard to escape the conclusion that amid the COVID-19 pandemic, the world has placed little priority on investing in HPSR.

\section{Lessons from history: three strategies for real change}

We contend that this needs to change if we are to avoid making the same mistakes that held back the global HIV/ AIDS response. Here we propose three ways forward for HPSR, derived from the Stuckler-McKee theory of social change in global health. ${ }^{16-18}$ This involves three elements that must converge for real change to happen: opening or exploiting a political window of opportunity, changing the conversation, and mobilising a campaign to drive the agenda. 


\section{Exploiting political windows of opportunity}

The first element of real change is already in place. The political window of opportunity could not open any wider. The world cannot afford to ignore COVID-19 and the solution must involve a large element of HPSR. Now is the time for change. Just as HIV led to the creation of the Global Fund for HIV, Malaria and TB, and the US President's Emergency Plan for AIDS Relief (PEPFAR), and encouraged a conversation on global solidarity, once again there is an opportunity for change. Slogans like "no-one is safe until everyone is safe" have real political momentum.

\section{Changing the conversation}

The second task is to change the conversation about HPSR. A quick scan of the language used in Englishlanguage articles about vaccines (using text analysis software Sketch Engine, English Web 2020: www. sketchengine.eu/ententen-english-corpus) reveals very little mention of investing in health systems. The words most commonly associated with vaccine(s) between January 2020 and September 2021 are 'develop', 'approve', 'distribute' and 'administer', with much weaker focus on 'transport' and others words related to building capacity on the ground.

A possible reason for HPSR not featuring prominently in the conversation about COVID-19 is that, as with HIV, donors do not have clarity about what they can do to strengthen health systems and are therefore reluctant to make appropriate investments to support efficient vaccine distribution in resource-poor settings. At least two things could be done to help 'make the case' for investing in HPSR. One is to better articulate the human impact of systems' investments. This is not always easy to do. Constructing a narrative about most interventions, such as introducing a new type of grain or building a well, is straightforward because it involves people, but a health system does not have an obvious face. When it works well, it is often in the background and silent. There are no villains or heroes in the 'master' narratives, or archetypal stories, such as 'rags to riches', 'overcoming the monster', or 'rebirth'. ${ }^{19}$ By introducing Maria's story we are illustrating what could be done more often by putting a human face on HPSR, and the human consequences when health systems fail.

Another approach to changing the conversation draws on techniques employed in marketing research: testing messages through real-world settings for engagement, via Facebook, Instagram and other social media. This approach has long been used by not-for-profit organisations, such as Oxfam and UNICEF, to hone their messaging strategies ${ }^{20}$, but is not well developed for HPSR campaigns.

\section{Mobilising a strategic campaign for change}

The third and final element is to mobilise resources and partners to drive the HPSR agenda. At least two strategies could help here. One is to show how investing in HPSR could help achieve the goals of powerful players in global health. The World Bank and International Monetary Fund have placed a priority on governance. Weaknesses in governance are pervasive in many health systems and reports by Transparency International's Global Corruption Reports series frequently identify the health sector as the most corrupt in a country. ${ }^{21}$ A series of strategic HPSR papers could tap these synergies. For example, for the World Bank, this could mean making the case that it will be impossible to assess a country's governance without investing in HPSR to assess corruption in the health sector. This argument would involve showing how health systems lack information to develop governance indicators and, since most countries' health sector is about $15-20 \%$ of GDP (estimates which do not even count the full income effects of health systems), it cannot be ignored. ${ }^{22}$ Another approach could be to link HPSR to G7 (Group of Seven) discussions about resilient health systems. Here, for example, a targeted position paper could make the case for how smart investments in HPSR can help build resilient health systems.

Another approach is to develop a certification tool, such as a Global Accountability Framework, to spark a conversation with leading funders about investing in HPSR and how best to support it and, ultimately, to hold these funders accountable for their decisions. These tools have played a substantial role in helping organise the agenda for climate change policy ${ }^{23}$, gender equity ${ }^{24}$, and many other pressing political issues that require coordinated, mobilised campaigns.

\section{Towards a better future?}

Maria lost her life in the service of others. "Even when she was in the hospital she was always on the go and helping people from her hospital bed," her son John said.

History doesn't have to repeat itself. The price of inaction on strengthening health systems to address HIV was staggering. And although we can't set those past mistakes to right, we can honour the legacy of those who suffered and prevent the same mistakes from happening again. We conclude with our challenge and core question: how many more stories like Maria's will we have to hear before we act?

\section{Acknowledgements}

This work was supported by the Alliance for Health Policy and Systems Research, World Health Organization. The authors are themselves alone responsible for the views expressed in the article. This article does not represent 
the views, decisions or policies of the Alliance for Health Policy and Systems Research.

\section{Peer review and provenance}

Externally peer reviewed, invited.

\section{Competing interests}

None declared.

\section{Author contributions}

DS drafted the original paper which was edited by MM and AK. All authors contributed to the background research on which this perspective is based.

\section{References}

1. European Medicines Agency. EMA recommends first COVID-19 vaccine for authorisation in the EU. The Netherlands: EMA; 2020 Dec 21 [cited 2021 Nov 2] Available from: www.ema.europa.eu/en/news/emarecommends-first-covid-19-vaccine-authorisation-eu

2. Euractiv. EU hits 200-million-jab milestone, with Malta first and Bulgaria last. Brussels: Euractiv; 2021 May 18 [cited 2021 Nov 2]. Available from: www.euractiv.com/section/ health-consumers/news/eu-hits-200-million-jab-milestonewith-malta-first-and-bulgaria-last/

3. World Health Organization Health Workforce Department. The impact of COVID-19 on health and care workers: a closer look at deaths. Geneva: WHO; Sep 2021 [cited 2021 Nov 2]. Available from: apps.who.int/iris/bitstream/ handle/10665/345300/WHO-HWF-WorkingPaper-2021.1eng.pdf

4. Statista. Share of adults who are fully vaccinated against COVID-19 in the European Economic Area (EA) as of October 28, 2021, by country. Hamburg, Germany: Statista; 2021 [cited 2021 Nov 2]. Available from: www. statista.com/statistics/1196071/covid-19-vaccination-ratein-europe-by-country/

5. Famuyiro TB, Ogunwale A, des Bordes J, Raji M. COVID-19: perceived infection risk and barriers to uptake of Pfizer-BioNTech and Moderna vaccines among community healthcare workers. J Racial Ethn Health Disparities. 2021:1-7.

6. Tagoe ET, Sheik N, Morton A, Nonvignon J, Sarker AR, Williams L, Megiddo I. COVID-19 vaccination in lowermiddle income countries: national stakeholder views on challenges, barriers, and potential solutions. Front Public Health. 2021;9:709127.

7. BMJ. Suspend intellectual property rights for covid-19 vaccines. BMJ. 2021:373:n1344.
8. Mwai P. Covid-19 vaccines: why some African states can't use their vaccines. UK: BBC; 2021 Jun 8 [cited 2021 Nov 2]. Available from: www.bbc.com/news/56940657

9. Shilts R. And the band played on: politics, people, and the AIDS epidemic. London: Souvenir Press; 2011.

10. Sabin CA. Do people with HIV infection have a normal life expectancy in the era of combination antiretroviral therapy. BMC Med. 2013;11:251.

11. Harries AD, Suthar AB, Takarinda KC, Tweya $H$, Kway NTT, Tayler-Smith K, Zachariah R. Ending the HIV/ AIDS epidemic in low- and middle-income countrys by 2030: is it possible? F1000Res. 2016;5:2328.

12. World Health Organization. Taking stock: health worker shortages and response to AIDS. Geneva: WHO; 2006 [cited 2021 Nov 2]. Available from: www.who.int/ healthsystems/task_shifting/TTR_response.pdf?ua $=1$

13. Macklin R, World Health Organization. Ethics and equity in access to HIV treatment -3 by 5 initiative. Geneva: WHO; 2004 [cited 2021 Oct 18]. Available from: www. who.int/ethics/en/background-macklin.pdf

14. Siciliani L, Wild C, McKee M, et al. Strengthening vaccination programmes and health systems in the European Union: a framework for action. Health Policy. 2020;124(5):511-8.

15. Stuckler D, Kentikelenis A, McKee M. The political determinants of health systems and policy research. Geneva: Alliance for Health Systems \& Policy Research, World Health Organization; WHO; 2021. Available from authors.

16. Stuckler D, Basu S, McKee M. International Monetary Fund and aid displacement. Int J Health Services. 2011;41(1): 67-76.

17. McKee M, Balabanova D, Basu S, Ricciardi W, Stuckler D. Universal health coverage: a quest for all countries but under threat in some. Value Health. 2013;16(1 Suppl):S39-45.

18. Geneau R, Stuckler D, Stachenko S, McKee M, Ebrahim S, Basu S, et al. Raising the priority of preventing chronic diseases: a political process. Lancet. 2010;376(9753):1689-98.

19. Booker C. The seven basic plots: why we tell stories. London: A\&C Black; 2004.

20. Google. Oxfam finds success with Google engagement ads. San Francisco: Google; 2013 [cited 2021 Oct 18]. Available from: www.thinkwithgoogle.com/marketingstrategies/video/case-study-oxfam

21. Transparency International. Global corruption report: corruption and health. London: Pluto Press; 2006 [cited 2021 Oct 18]. Available from: images.transparencycdn. org/images/2006_GCR_HealthSector_EN.pdf 
22. Organisation for Economic Co-operation and Development. Health statistics 2021. Paris: OECD; 2021 [cited 2021 Oct 18]. Available from: www.oecd.org/els/ health-systems/health-data.htm

23. Accountability Framework. Accountability Framework Initiative. US: AFi coalition; 2021 [cited 2021 Nov 2]. Available from: accountability-framework.org/
24. Inter-Agency Standing Committee. IASC gender accountability framework report 2019. New York: UN Women; 2020 [cited 2021 Oct 18]. Available from: interagencystandingcommittee.org/system/files/2021-04/ IASC\%20Gender\%20Accountability\%20Framework\%20 Report\%202019.pdf/ 